\title{
The effect of pyrolytic carbon black prepared from junked tires on the properties of ethylene-propylene-diene copolymers (EPDM)
}

\author{
A. $D u^{1 *}, Z$. Zhang ${ }^{2}, M . W u^{1}$ \\ ${ }^{1}$ Key Laboratory of Rubber-plastics, Ministry of Education, Qingdao University of Science \& Technology, Qingdao \\ 266042, China \\ ${ }^{2}$ Xuzhou College of Industrial Technology, Xuzhou 221140, China
}

Received 6 January 2009; accepted in revised form 4 March 2009

\begin{abstract}
Pyrolytic carbon black (PCB) made from used tires was used in ethylene-propylene-diene copolymers (EPDM). The microstructure of PCB was characterized by scanning electron microscopy (SEM). PCB was compounded with EPDM to prepare EPDM vulcanizates. The effects of PCB on the processing properties of EPDM compounds and the mechanical properties of vulcanizates were investigated and compared with other traditional fillers such as semi-reinforcing furnace black (N774), light calcium carbonate $\left(\mathrm{CaCO}_{3}\right)$ and thermal black (N990). At the same time, the rheological behavior of EPDM compounds filled with different fillers was characterized by capillary rheometrics. The SEM photos showed that the particle shape was quiet different from that of $\mathrm{CaCO}_{3}$ and $\mathrm{N} 990$, it was similar to that of N774. The primary particle size was smaller than that of N774, but the aggregate size of PCB was larger than that of N774. The effect of PCB on the processing properties of EPDM compounds was similar to that of other fillers. Among the four fillers, PCB imparted EPDM compounds with higher Mooney viscosity. With the increase of filler content, the scorch time and optimum curing time of EPDM compounds changed little. The reinforcing effect of PCB was similar to that of N990, but inferior to that of N774. With the increase of PCB content, tensile strength, tear strength, and modulus at $100 \%$ elongation of EPDM vulcanizates increased significantly. When EPDM was filled with $50 \mathrm{phr}$ PCB, the tear strength of EPDM vulcanizates increased by 3 times, compared with that of EPDM gum vulcanizates. The appearance of EPDM extrudate filled with PCB was coarser than that of other fillers.
\end{abstract}

Keywords: mechanical properties, rubber, reinforcements, pyrolytic carbon black, ethylene-propylene-diene copolymer

\section{Introduction}

The demand for tires is increasing rapidly with the development of the car industry. At the same time, the amount of used tires is also increasing rapidly. The disposal of used tires has become an important issue worldwide and represents a major environmental problem. At present there are three kinds of methods for the reclamation of used tires; they are retreading, recycling and pyrolysis [1]. The former two methods are not the final disposal of the used tires. Pyrolysis processing of used tires is consid- ered to be an environmentally acceptable and promising disposal method with its high-energy recovery and low pollution emission.

The main pyrolytic products of used tires are pyrolytic oil, pyrolytic gas and pyrolytic carbon black (PCB). Many scholars [2-8] home and abroad have studied the pyrolysis technology and characterized the properties of PCB. Many researchers [9-11] investigated the specific surface area and porosity of PCB. PCB can be used as fuel or as fillers in asphalt and rubbers [12-14]. There 
are few reports about PCB used in rubbers. In recent years, Peng and Xiao [15] investigated the superfine grinding and surface chemical modification of PCB, and studied the effect of modified PCB on the properties of NR (natural rubber) vulcanizates. Our previous work investigated the basic characteristics of PCB and the effects of PCB on the properties of SBR (stryene butadiene rubber) [16]. In this paper, we compare the microstructure of PCB, N774, N990 and $\mathrm{CaCO}_{3}$, and focus our efforts on the application of PCB in EPDM. As EPDM is a non-self-reinforcing rubber, the tensile strength of gum vulcanizates was very low. It is widely used for extruding products, such as hose and sealing strip. Various fillers showed obvious reinforcement for it. The effect of PCB on the processing properties of EPDM compounds and the mechanical properties of EPDM vulcanizates were systematically studied and compared with that of traditional carbon black and inorganic fillers.

\section{Experimental}

\subsection{Materials}

Ethylene-propylene-diene rubber (EPDM 2340A) was supplied by DSM, semi-reinforcing furnace carbon black (N774), was product of Qingdao Degussa Chem. Co. Ltd, China; thermal carbon black (N990), was product of Cabot Co., pyrolytic carbon black prepared from used tires (PCB) was supplied by Jinan Wanda New Energy Source Co. Ltd. (China), other agents were all industrial grades.

\subsection{Morphology observation of PCB}

PCB powder and other fillers were coated with a thin gold layer and examined with a JSM 6700F scanning electron microscope (SEM).

\subsection{Compounding and sample preparation}

The mixtures of rubber and all kinds of additives were prepared on a two-roller mill at room temperature. All the samples were based on 100 parts by weight of rubber. At first, activating agents (zinc oxide and stearic acid) were added into rubbers. After dispersion, fillers (N990, N774, PCB or $\mathrm{CaCO}_{3}$ ) were added into the compounds. At last, the dicumyl peroxide (DCP) and triallyl isocyanu- rate (TAIC) were added. The compounds were press-cured to a $2 \mathrm{~mm}$ thick sheet at $170^{\circ} \mathrm{C}$ according to the curing time predicted by the vulkameter (UCAN EK-2000P from Taiwan).

\subsection{Rheological behavior}

Mooney viscosity $\left(\mathrm{ML}_{1+4}\right.$ at $\left.100^{\circ} \mathrm{C}\right)$ of the compounds was determined on an automated Mooney viscometer (UCAN EK-2000M from Taiwan) according to ISO 289-1. Curing characteristics were measured at $170^{\circ} \mathrm{C}$ using a moving-die rheometer (UCAN EK-2000P from Taiwan) according to ISO 3417.

Rheological behavior was characterized by capillary rheometry (Model RH2000, from Bohlin Company of England). Slenderness ratios of capillary are 16:1 and 0.4:1, respectively. The appearance of extrudate was observed by optical microscope (Model BX 51, from Olympus Company of Japan).

\subsection{Measurement of mechanical properties}

Tensile properties were measured with dumbbell specimens. The length of specimen was $75 \mathrm{~mm}$ and the cross section were $4 \mathrm{~mm}$ (width) $\times 2 \mathrm{~mm}$ (thickness) according to ASTM D412. Tear strength was tested according to ASTM D624 using an unnotched $90^{\circ}$ angle test piece. Both tensile and tear tests were performed on an GT-AI-7000S (Guangzhou, China) material tester at a crosshead speed of $500 \mathrm{~mm} / \mathrm{min}$. Shore A hardness was determined using a hand-held Shore A Durometer according to ASTM D2240. All tests were carried out at $23^{\circ} \mathrm{C}$.

\section{Results and discussion}

\subsection{SEM photos of fillers}

Figures 1a to 1d are SEM photos of N774 and PCB respectively. Seen from Figure 1, the particle shape of PCB is similar to that of N774, but quite different from that of $\mathrm{N} 990$ and $\mathrm{CaCO}_{3}$. The particles of N990 are round and uniform, while the microstructure of $\mathrm{CaCO}_{3}$ is flaky. The aggregation size of PCB $(\sim 10 \mu \mathrm{m})$ is obviously larger than that of N774 $(\sim 2 \mu \mathrm{m})$. At the same time, the size of N774 particle aggregation is uniform and the size distribution is narrow. Seen from Figures $1 \mathrm{c}$ and $1 \mathrm{~d}$, the basic fundamental particles of PCB are smaller 


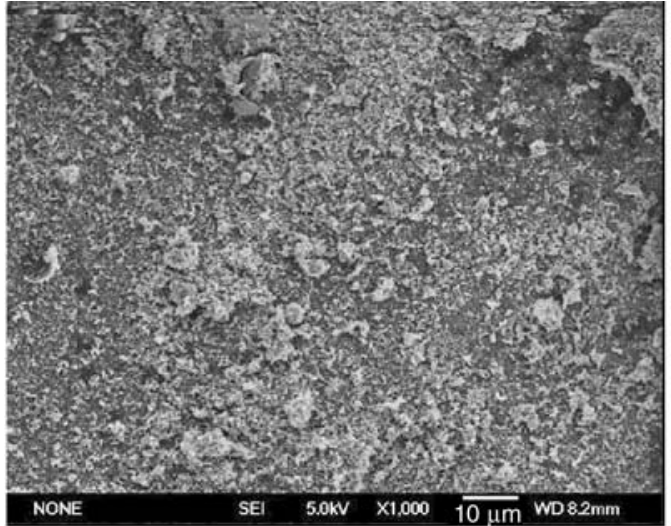

a)

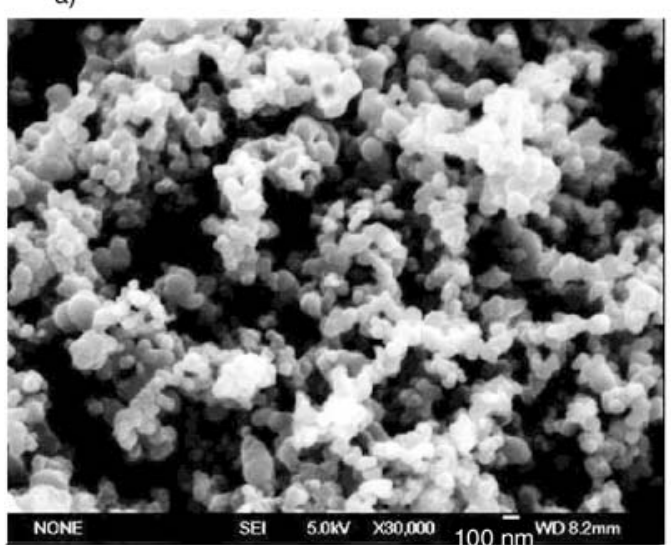

c)

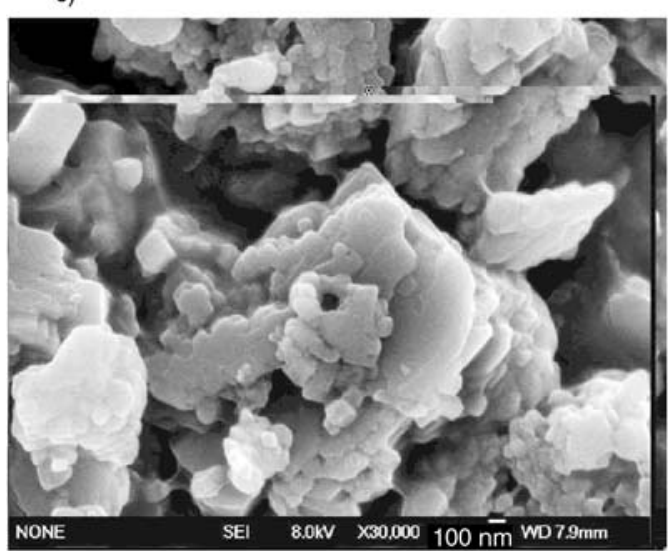

e)

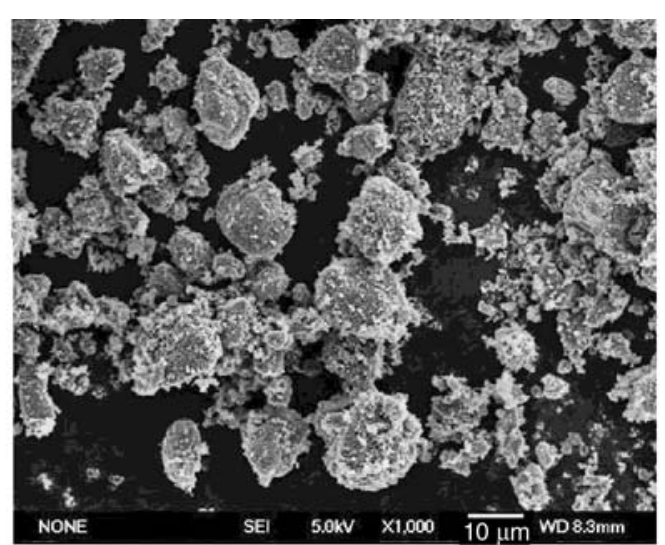

b)

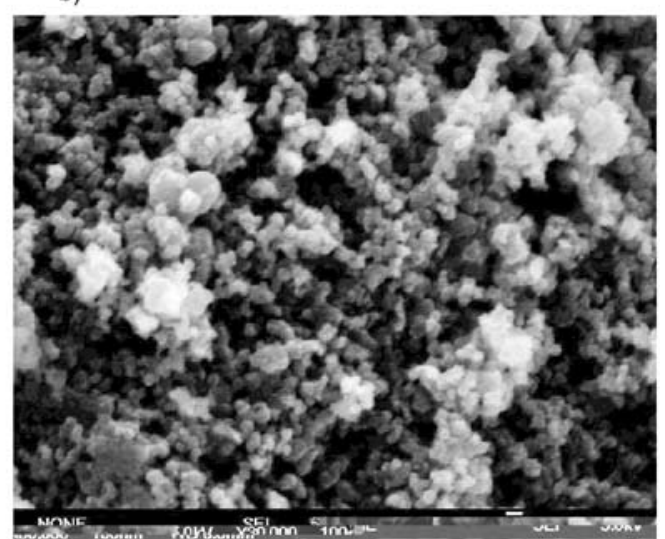

d)

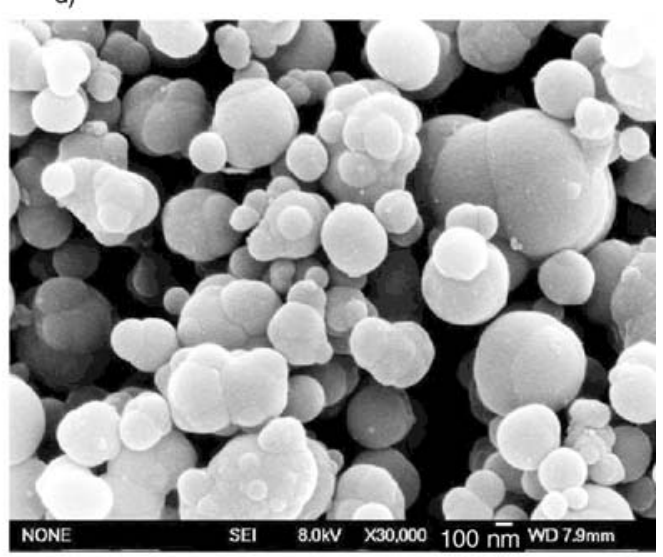

f)

Figure 1. The microstructure of fillers a) N774 (×1 000); b) PCB (×1 000); c) N774 (×30 000); d) PCB (×30 000); e) $\mathrm{CaCO}_{3}(\times 30$ 000); f) $\mathrm{N} 990(\times 30$ 000)

than that of N774, but the size distribution of PCB is wider than that of N774. Compared with the particles of $\mathrm{CaCO}_{3}$ and $\mathrm{N} 990$, the particle size of PCB is much smaller.

\subsection{The application of PCB in EPDM}

As is well known, commercial carbon blacks show obvious reinforcing effects for rubbers. PCB is sim- ilar to commercial carbon blacks in the constitution and structure, although the ash content of PCB is more than that of other carbon blacks [16]. Here we investigate the effect of PCB on the processing and mechanical properties of EPDM vulcanizate, and, at the same time compare it with commercial carbon blacks (such as N990 and N774) and inorganic filler $\left(\mathrm{CaCO}_{3}\right)$. 


\subsubsection{Effect of fillers on the curing characteristics and Mooney viscosity of EPDM compounds}

The effects of different fillers on the Mooney viscosity of EPDM compounds are shown in Figure 2. The Mooney viscosities of EPDM compounds increase with the incorporation of all four kinds of fillers. The Mooney viscosities of EPDM compounds filled with $\mathrm{PCB}$ is obviously higher than those of EPDM compounds filled with $\mathrm{CaCO}_{3}$, N990 and N774. The magnitude of Mooney viscosity of EPDM filled with different fillers is as follows: $\mathrm{PCB}>\mathrm{N} 774>\mathrm{N} 990>\mathrm{CaCO}_{3}$. As well known, the effect of the particle size of filler on the Mooney viscosity of compounds is more obvious than other factors such as structure and surface activity. As shown in Figure 1, the primary particle of PCB is smaller than that of N774, which leads to the higher Mooney viscosity of EPDM compounds. The effects of different fillers on the curing characteristics of EPDM compounds are shown in Table 1. With the incorporation of fillers into EPDM, the lowest torque $\left(M_{L}\right)$ and highest torque $\left(M_{H}\right)$ of EPDM compounds increase. In general, $M_{H}-M_{L}$ reflects the curing state of compounds and the reinforcing effect of fillers. Here the values of $M_{H}-M_{L}$ increase with the amount of fillers. It indicates that four fillers show obvious reinforcing effect for EPDM. Compared with gum compounds, the scorch time $\left(t_{s 1}\right)$ and the optimum curing time $\left(t_{c 90}\right)$ of EPDM compounds filled with different fillers shorten. Because the four kinds of fillers are weakly alkaline, they accelerate curing. But with the increase of filler content, the $t_{c 90}$ of EPDM compounds filled with different fillers change little.

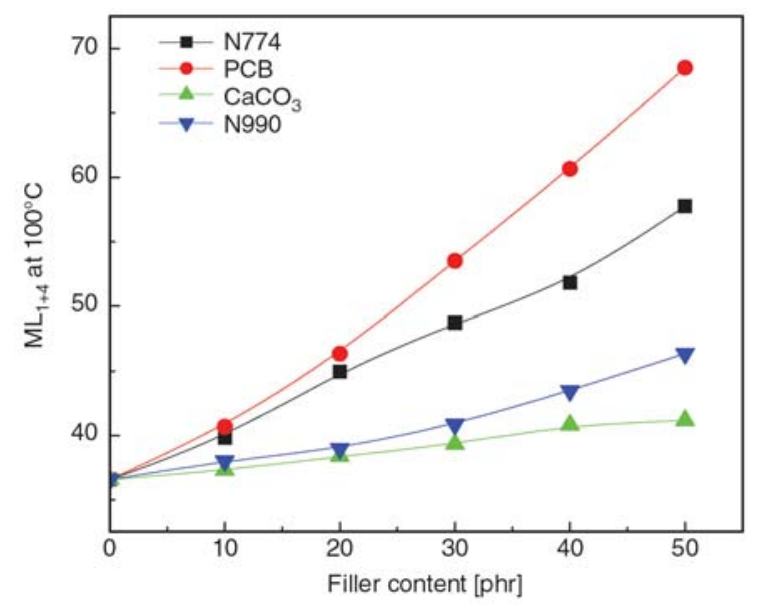

Figure 2. The effect of different fillers on the Mooney viscosity of EPDM compounds
Table 1. The curing characteristics of EPDM compounds at $170^{\circ} \mathrm{C}$

\begin{tabular}{|c|c|c|c|c|}
\hline Sample & $\begin{array}{c}\mathbf{M}_{\mathbf{L}} \\
{[\mathrm{Ncm}]}\end{array}$ & $\begin{array}{c}\mathbf{M}_{\mathbf{H}} \\
{[\mathrm{Ncm}]}\end{array}$ & $\begin{array}{c}\mathbf{t}_{\mathrm{c10}} \\
{[\mathrm{min}]}\end{array}$ & $\begin{array}{c}\mathbf{t}_{\mathbf{c 9 0}} \\
{[\mathrm{min}]}\end{array}$ \\
\hline 1 & 3.2 & 151.6 & 1.05 & 14.10 \\
\hline 2 & 3.6 & 161.0 & 0.97 & 12.10 \\
\hline 3 & 3.4 & 184.5 & 1.05 & 12.35 \\
\hline 4 & 3.6 & 194.9 & 1.08 & 13.00 \\
\hline 5 & 4.0 & 193.2 & 1.00 & 12.27 \\
\hline 6 & 4.3 & 205.2 & 1.02 & 12.47 \\
\hline 7 & 3.5 & 177.7 & 1.12 & 12.08 \\
\hline 8 & 4.4 & 196.3 & 0.88 & 12.11 \\
\hline 9 & 5.0 & 228.9 & 0.92 & 11.65 \\
\hline 10 & 6.2 & 246.0 & 0.92 & 11.95 \\
\hline 11 & 7.0 & 266.6 & 0.93 & 11.65 \\
\hline 12 & 3.8 & 178.4 & 1.10 & 13.20 \\
\hline 13 & 4.0 & 188.5 & 1.07 & 12.77 \\
\hline 14 & 4.4 & 210.9 & 1.07 & 12.53 \\
\hline 15 & 4.4 & 233.3 & 1.05 & 12.25 \\
\hline 16 & 4.9 & 256.2 & 1.03 & 12.50 \\
\hline 17 & 4.2 & 178.8 & 0.97 & 12.12 \\
\hline 18 & 5.2 & 196.2 & 0.95 & 12.13 \\
\hline 19 & 6.3 & 212.4 & 0.87 & 12.20 \\
\hline 20 & 7.6 & 225.0 & 0.90 & 12.07 \\
\hline 21 & 10.1 & 243.0 & 0.88 & 11.20 \\
\hline
\end{tabular}

Note: $1^{\#} \quad$ represents the gum compounds (no filler);

2-6" represent EPDM compounds filled with $\mathrm{CaCO}_{3}$ (the amount of $\mathrm{CaCO}_{3} 10-50 \mathrm{phr}$ );

7-11\# represent EPDM compounds filled with N774 (the amount of N774 10-50 phr);

12-16" represent EPDM compounds filled with N990 (the amount of N990 10-50 phr);

17-21" represent EPDM compounds filled with PCB (the amount of PCB 10-50 phr)

\subsubsection{Effect of fillers on the rheological behavior of EPDM compounds}

The viscous activation energy of EPDM compounds

The variation in viscosity of polymer with temperature complies with the Arrhenius equation (Equation (1)):

$\eta=A \cdot e^{\Delta E_{\eta} / R T}$

where $A$-constant; $\Delta E_{\eta}$ - viscous activation energy; $R$ - gas constant; $T$ - absolute temperature. The logarithmic format of Equation (1) is given in Equation (2):

$\ln \eta=\ln A+\frac{\Delta E_{\eta}}{R T}$

The $\ln \eta-T^{-1}$ plots of EPDM compounds filled with different fillers are shown in Figure 3. As seen from Figure $3, \ln \eta$ is linear with $T^{-1}$. According to Equa- 


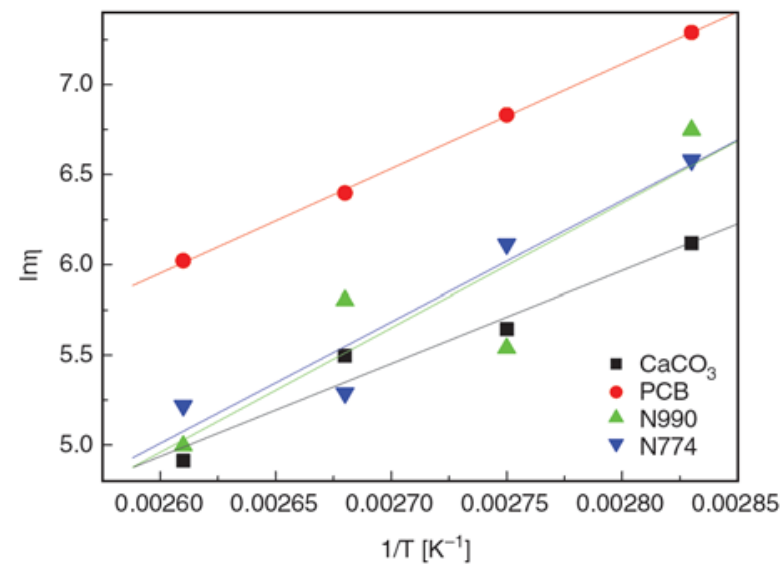

Figure 3. The $\ln \eta-T^{-1}$ plot of EPDM compounds filled with different fillers

tion (2), we can obtain the viscous activation energy of EPDM compounds, as shown in Table 2. $\Delta E_{\eta}$ reflects the minimum energy that the motion of macromolecule needs to overcome the interaction
Table 2. The viscous activation energy of EPDM compounds filled with different fillers

\begin{tabular}{|c|c|}
\hline Fillers & $\boldsymbol{\Delta E}_{\boldsymbol{\eta}}[\mathbf{k J} / \mathbf{m o l}]$ \\
\hline $\mathrm{CaCO}_{3}$ & 42.86 \\
\hline $\mathrm{PCB}$ & 48.32 \\
\hline $\mathrm{N} 990$ & 57.45 \\
\hline $\mathrm{N} 774$ & 55.97 \\
\hline
\end{tabular}

force between molecules. $\Delta E_{\eta}$ of EPDM filled with PCB is less than that of EPDM filled with N990 and N774, but greater than that of EPDM filled with $\mathrm{CaCO}_{3}$. It reveals that the reinforcing effect of PCB is inferior to that of N990 and N774, superior to that of $\mathrm{CaCO}_{3}$.

\subsubsection{The appearance of EPDM extrudate at different shearing rates}

Figure 4 shows the appearance of EPDM extrudate at different shearing rates. As seen from Figure 4,

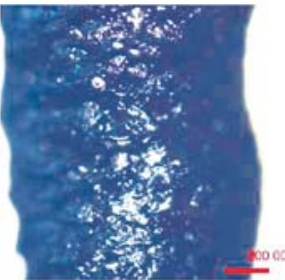

a-1

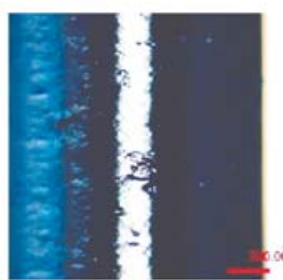

b-1

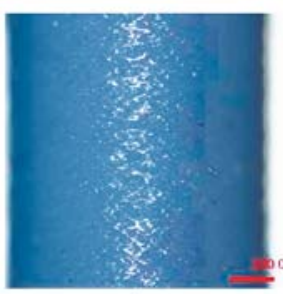

c-1

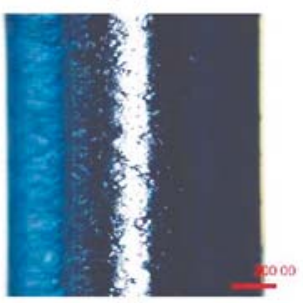

d-1
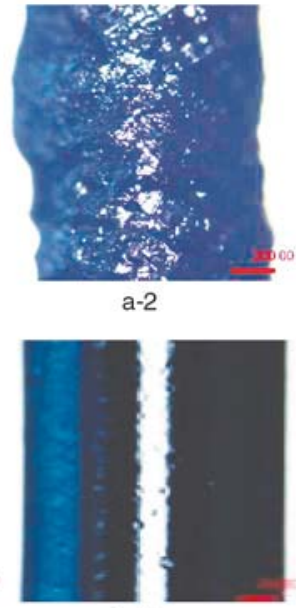

b-2

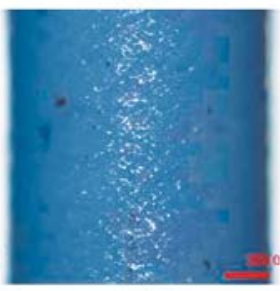

c-2

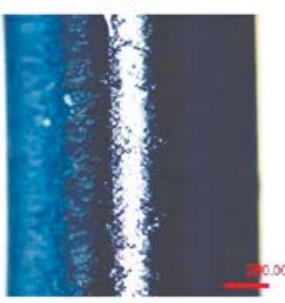

d-2

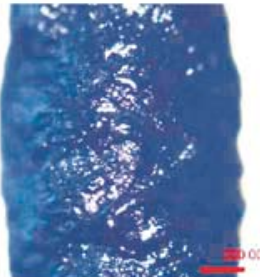

a-3

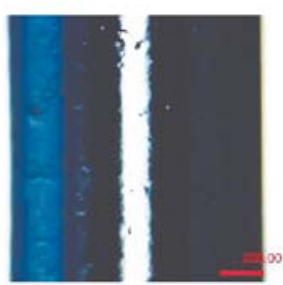

b-3

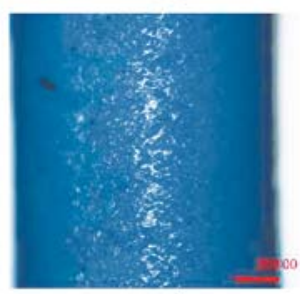

c-3

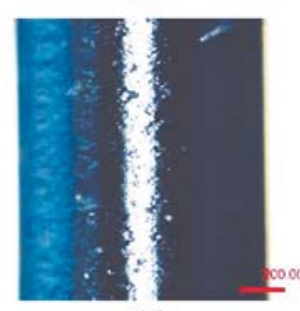

d-3

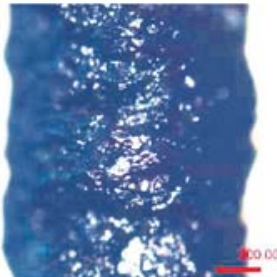

a-4

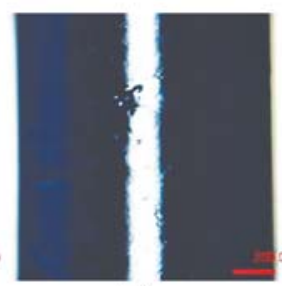

b-4

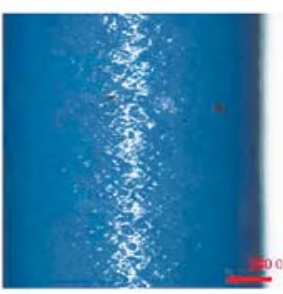

c-4

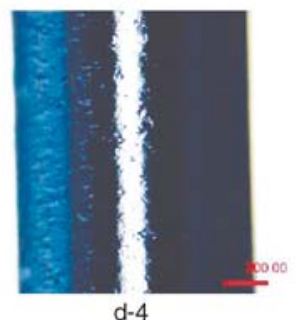

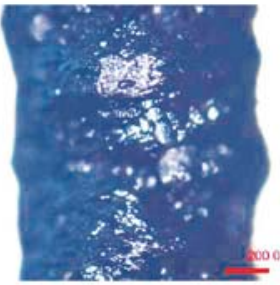

a-5

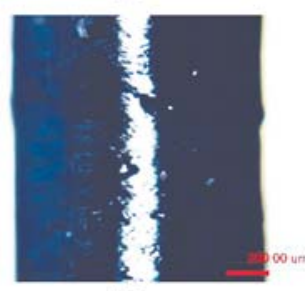

b-5

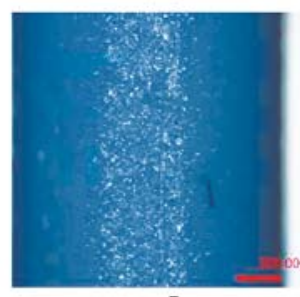

c-5

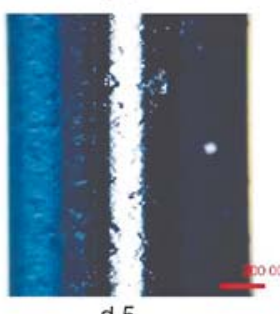

Figure 4. The surface appearance of EPDM compounds filled with different fillers at $110^{\circ} \mathrm{C}$. a) EPDM/PCB compounds; b) EPDM/N990 compounds; c) EPDM/CaCO 3 compounds; d) EPDM/N774 compounds. Shearing rate/s: $1-23.06 ; 2-60.62 ; 3-163.92 ; 4-465.84 ; 5-1436.93$. 
the appearance of EPDM compounds filled with $\mathrm{CaCO}_{3}, \mathrm{~N} 990$, and N774 is smooth at low shearing rate. Even at high shearing rate, the appearance is still smooth. While the appearance of EPDM compound filled with PCB is coarse even at low shearing rate. The appearance of PCB filled EPDM compound is sausage-like. The poor appearance of PCB filled EPDM compound results from the higher Mooney viscosity of compounds. The higher the Mooney viscosity, the poorer the extruding performance.

\subsubsection{Effect of different fillers on the mechanical properties of EPDM vulcanizates}

The effects of different fillers on the mechanical properties of EPDM vulcanizates are shown in Figure 5. The four kinds of fillers showed different reinforcing effect for EPDM vulcanizates. With the increase of fillers content, the tensile strength of EPDM vulcanizates is gradually improved. Compared with the other kinds of carbon blacks (N990 and N774), the tensile strength of EPDM vulcanizates filled with PCB is lower than that of N774, and approaches to that of N990. Among the four kinds of fillers, $\mathrm{CaCO}_{3}$ shows little reinforcing effect for EPDM vulcanizates. The tensile strength of EPDM vulcanizates change little with the incorporation of $\mathrm{CaCO}_{3}$ into EPDM vulcanizates. The tear strength of EPDM vulcanizates is greatly improved with the increase of filler content, as shown in Figure 5b. The fillers show different effects on the tear strength of EPDM vulcanizates: $\mathrm{N} 774>\mathrm{PCB}>\mathrm{N} 990>\mathrm{CaCO}_{3}$. When the amount of PCB is $50 \mathrm{phr}$, the tear strength of EPDM vulcanizate is about $22 \mathrm{kN} \cdot \mathrm{m}^{-1}$, which is greater than that of $\mathrm{N} 990$ and $\mathrm{CaCO}_{3}$, approaches to that of N774. Compared with that of gum vulcanizates, the tear strength of EPDM vulcanizates filled $50 \mathrm{phr}$ PCB improved by 3 times. Although the primary particle size of PCB is smaller than that of N774, the reinforcing effect of PCB for EPDM is inferior to that of N774. It is attributed to the surface activity of filler. During the pyrolysis of used tires, the carbonaceous residue formed deposites on the surface of PCB, which covers the surface active sites of PCB [17].
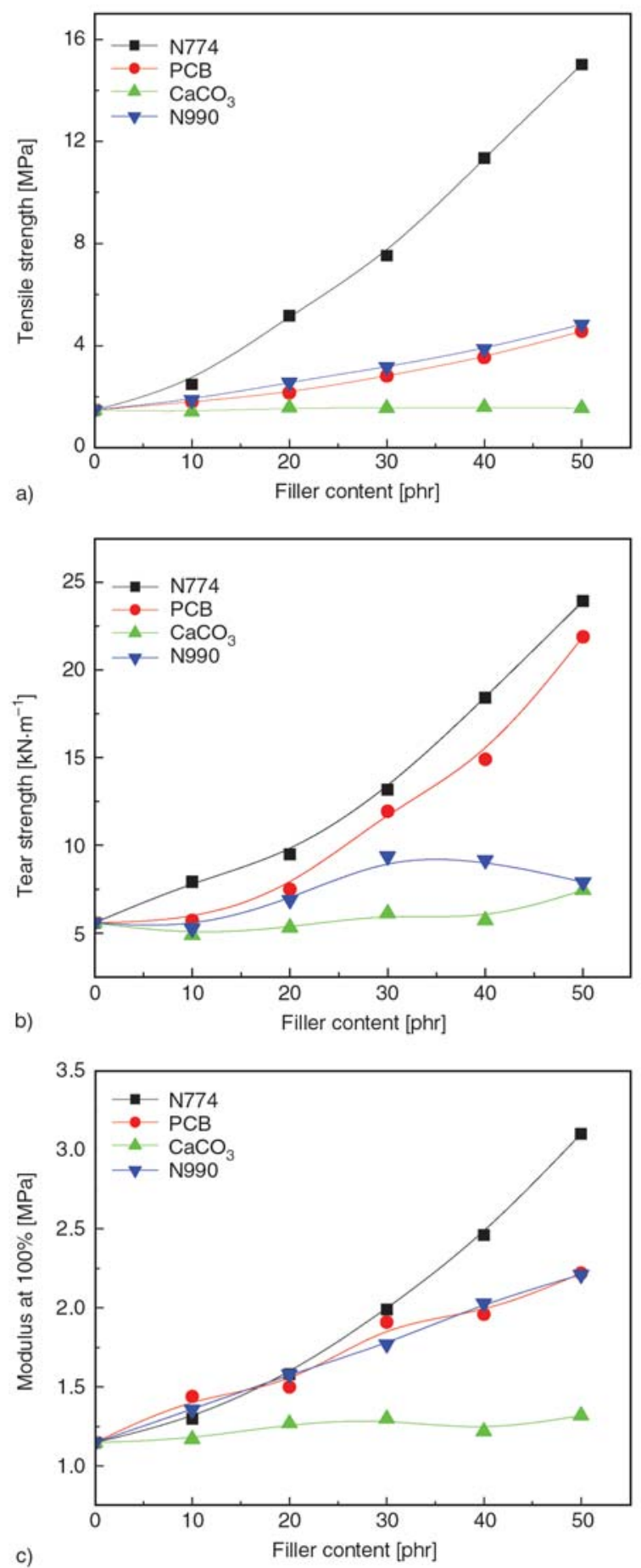

Figure 5. The effect of different fillers on the mechanical properties of EPDM vulcanizates

\section{Conclusions}

1) SEM photos indicate that the particle shape of $\mathrm{PCB}$ is quite different from that of $\mathrm{N} 990$ and $\mathrm{CaCO}_{3}$, but similar to that of $\mathrm{N} 774$. The primary particle size of $\mathrm{PCB}$ is smaller than that of N774, but the aggregate size of PCB is larger than that of N774, and the size distribution is wider. 
2) The effect of $\mathrm{PCB}$ on the processing properties of EPDM compounds is similar to that of other traditional carbon blacks. The variation of Mooney viscosity and curing characteristic of compounds with PCB content is similar to that of other general fillers (for example N990, N774 and $\mathrm{CaCO}_{3}$ ). With the incorporation of fillers into EPDM, the scorch time and optimum curing time of EPDM compounds change little, while the Mooney viscosity increases.

3) With the increase of PCB content, the tensile strength, tear strength, modulus at $100 \%$ elongation of EPDM vulcanizates are greatly improved. With the increase of filler content, the tensile strength of EPDM vulcanizates filled with PCB approach to that of N990, while the tear strength of EPDM vulcanizates filled with PCB is superior to that of N990, and approach to that of N774. When the amount of PCB increases from 10 to $50 \mathrm{phr}$, the tear strength of EPDM vulcanizates increased by 3 times.

4) The appearance of EPDM compounds filled with PCB is sausage-like, and coarser than that of other fillers.

\section{References}

[1] Fan R. D.: Integrate utilizing technology of scrap rubber (Chinese). Chemical Industry Press, Beijing, (1989).

[2] Olazar M., Araboiurrutia M., López G., Aguado R., Bilbao J.: Effect of acid catalysts on scrap tyre pyrolysis under fast heating conditions. Journal of Analytical and Applied Pyrolysis, 82, 199-204 (2008).

DOI: 10.1016/j.jaap.2008.03.006

[3] Rofigul Islam M., Tushar M. S. H. K., Haniu H.: Production of liquid fuels and chemicals from pyrolysis of Bangladeshi bicycle/rickshaw tire wastes. Journal of Analytical and Applied Pyrolysis, 82, 96-109 (2008).

DOI: $10.1016 /$ j.jaap.2008.02.005

[4] Helleur R., Popovic N., Ikura M., Stanciulescu M., Liu D.: Characterization and potential applications of pyrolytic char from ablative pyrolysis of used tires. Journal of Analytical and Applied Pyrolysis, 58-59, 813-824 (2001).

DOI: $10.1016 / \mathrm{S} 0165-2370(00) 00207-2$

[5] Kaminsky W., Mennerich C.: Pyrolysis of synthetic tire rubber in a fluidized-bed reactor to yield 1,3-butadiene, styrene and carbon black. Journal of Analytical and Applied Pyrolysis, 58-59, 803-811 (2001). DOI: $10.1016 / \mathrm{S} 0165-2370(00) 00129-7$
[6] Cunliffe A. M., Williams P. T.: Composition of oils derived from the batch pyrolysis of tires. Journal of Analytical and Applied Pyrolysis, 44, 131-152 (1998). DOI: $10.1016 / \mathrm{S} 0165-2370(97) 00085-5$

[7] Teng H., Serio M. A., Wojtowicz M. A., Bassilakis R., Solomon P. R.: Reprocessing of used tires into activated carbon and other products. Industrial and Engineering Chemistry Research, 34, 3102-3111 (1995). DOI: $10.1021 / \mathrm{ie} 00048 \mathrm{a} 023$

[8] Yang Y. R., Lü J., Chen B. C.: Surface characteristics of carbon black produced by pyrolysis of used tires (Chinese). Acta Scientiae Circumstantiae, 22, 637640 (2002).

[9] Ogasawaro S., Kuroda M., Wakai N.: Preparation of activated carbon by thermal decomposition of used automotive tires. Industrial and Engineering Chemistry Research, 26, 2552-2556 (1987). DOI: $10.1021 / \mathrm{ie} 00072 \mathrm{a} 030$

[10] Merchant A. A., Petrich M. A.: Pyrolysis of scrap tires and conversion of chars to activated carbon. AIChE Journal, 39, 1370-1376 (1993). DOI: 10.1002/aic.690390814

[11] Miguel G. S., Fowler G. D., Dall'Orso M., Sollars C. J.: Porosity and surface characteristics of activated carbons produced from waste tire rubber. Journal of Chemical Technology and Biotechnology, 77, 1-8 (2001).

[12] Yousefi A. A., Ait-Kadi A., Roy C.: Effect of usedtire-derived pyrolytic oil residue on the properties of polymer-modified asphalts. Fuel, 79, 975-986 (2000) DOI: 10.1016/S0016-2361(99)00216-1

[13] Leblanc J. L., Roy C., Mirmiran S., Benallal B., Schwerdtfeger A. E.: The plasticizing properties of heavy oils obtained from the vacuum pyrolysis of used tires. Kaustschuk Gummi Kunststoffe, 49, 194-199 (1996).

[14] Roy C., Chaala A., Darmstadt H.: The vacuum pyrolysis of used tires end-uses for oil and carbon black products. Journal of Analytical and Applied Pyrolysis, 51, 201-221 (1999). DOI: $10.1016 / \mathrm{S} 0165-2370(99) 00017-0$

[15] Peng X. Q., Xiao G. L.: Further processing and application of pyrolytic carbon black of used tires (Chinese). Polymer Materials: Science and Engineering, 20, 142-144 (2004).

[16] Du A. H., Wu M. S., Su C. Y., Chen H.: The characterization of pyrolytic carbon black prepared from used tires and its application in styrene-butadiene rubber (SBR). Journal of Macromolecule Science, Part B Physics, 47, 268-275 (2008). DOI: $\underline{10.1080 / 00222340701748768}$

[17] Darmstadt H., Roy C., Kaliaguine S., Xu G., Auger M., Tuel A., Ramaswamy V.: Solid state ${ }^{13}$ C-NMR spectroscopy and XRD studies of commercial and pyrolytic carbon blacks. Carbon, 38, 1279-1287 (2000).

DOI: $\underline{10.1016 / S 0008-6223(99) 00259-6}$ 